\title{
Editorial
}

Digestion

\section{Heme Oxygenase and Hepatic Microcirculation: More than Just Carbon Monoxide?}

\author{
Gavin E. Arteel \\ Department of Pharmacology and Toxicology and the University of Louisville Alcohol Research Center, \\ University of Louisville Health Sciences Center, Louisville, K.Y., USA
}

Hepatic microcirculatory tone is a complex and dynamic process that is mediated by the balance of local and systemic vasoconstrictor and vasodilators. Dysregulation of hepatic microcirculatory tone is not only involved in acute liver injury (e.g. hemorrhagic shock, ischemia/ reperfusion injury, organ transplantation, etc.) [1], but is also responsible for many of the sequelae associated with chronic liver diseases (e.g. ascites, esophageal varices, etc.) [2]. Therefore, understanding of the mechanisms behind the maintenance of this tone has direct implications to several clinical situations.

Activated Kupffer cells release several vasoactive compounds that can directly or indirectly alter hepatic vascular tone. Indeed, in previous work, Steib et al. [3] demonstrated that activation of Kupffer cells (the resident hepatic macrophages) with zymosan A, causes hepatic vasoconstriction mediated, at least in part, by thromboxane $\mathrm{A}_{2}\left(\mathrm{TxA}_{2}\right)$. Here [4], the authors build on this model and investigate the role of nitric oxide (NO $\left.{ }^{\circ}\right)$ from nitric oxide synthases (NOS) and carbon monoxide $\left(\mathrm{CO}^{\circ}\right)$ from heme oxygenase-1 (HO-1) in mediating hepatic microcirculatory changes under these conditions. Both gases are vasodilators that have been shown to rescue livers from vasoactive stimuli in several models. $\mathrm{NO}^{\circ}$ is assumed to mediate its effects predominantly via activating guanylate cyclase to produce cyclic guanosine monophosphate

\section{KARGER}

Fax +4161306 1234

E-Mail karger@karger.ch

www.karger.com
(C) 2013 S. Karger AG, Basel

0012-2823/13/0872-0100\$38.00/0

Accessible online at:

www.karger.com/dig
(cGMP). Like $\mathrm{NO}^{*}, \mathrm{CO}^{*}$ can also activate guanylate $\mathrm{cy}$ clase to cause vasodilation [5]; however, previous studies have indicated that other mechanisms may contribute to the effects of $\mathrm{CO}^{\circ}$ on hepatic tone [6]. In their study [4], the authors found some potentially novel mechanisms by which HO-1 mediates hepatic tone that appear independent of cGMP and, at least in part, independent of $\mathrm{CO}^{\circ}$.

The authors employed the isolated perfused rat liver. Although this model does not recapitulate all aspects that regulate hepatic tone (e.g. the liver is not innervated), the advantages of this perfusion model outweigh the limitations. Specifically, all normal intrahepatic communications are assumedly intact in an organ in which the perfusion flow is mimicking the in vivo situation [7]. The authors showed that the TLR agonist zymosan A caused a robust increase in portal pressure [see fig. 1a, 4] that is rapidly, albeit incompletely, compensated by the liver. Under these conditions, $\mathrm{NO}^{\circ}$ did not appear to play a primary role in the portal pressure changes; although inhibiting NOS with L-NAME increased the pressure response caused by zymosan A, the shape of the curve was not altered and the pressure returned to almost basal within a similar timeframe. Likewise, adding exogenous cGMP (8-Br-cGMP) did not alter the increase in portal pressure caused by zymosan A, although it blunted the L-NAME effect. 
In contrast to NOS, inhibiting HO-1 profoundly affected not only the increase in pressure, but also the shape of the curve in response to zymosan A [see fig. 2a, 4]; the liver did not recover from the increase in pressure within the timeframe of the experiment $(100 \mathrm{~min})$. This effect appeared to be partially independent of $\mathrm{CO}^{\circ}$ and nonresponsive to exogenous cGMP. These effects did, however, correlate with production of $\mathrm{TXB}_{2}$ and $\mathrm{PGD}_{2}$, and could be attenuated by COX inhibition with indomethacin. The authors proposed that the prevention of heme degradation by inhibiting HO-1 increases the supply of heme for COX activation. This is distinctly possible and certainly supported by the data presented.

Although the authors have found a potentially novel mechanism of action of $\mathrm{HO}-1$ in their study, there are several unanswered questions that should be addressed in future work to fill gaps in our understanding. For example, as mentioned in the Discussion section [4], both $\mathrm{HO}-1$ and $\mathrm{CO} \cdot$ can protect against oxidative stress, which can impair hepatic microcirculation. Furthermore, Amersi et al. [6] observed cGMP-independent effects of CO ${ }^{*}$ in a perfusion model of ischemia/reperfusion injury. In that study, exogenous $\mathrm{CO}^{\circ}$ protected against elevated portal pressure via preventing hepatic cell death during the reperfusion phase. The authors of the current study have no indices of liver injury in their model [4]. Nevertheless, this work supplies proof-of-concept that HO-1 inhibition should not be considered synonymous with inhibition of $\mathrm{CO}^{\circ}$ production and that other mechanisms may come into play when studying hepatic vascular tone.

\section{References}

$>1$ Vollmar B, Menger MD: The hepatic microcirculation: mechanistic contributions and therapeutic targets in liver injury and repair. Physiol Rev 2009;89:1269-1339.

$>2$ Poca M, Puente A, Graupera I, Villanueva C: Prognostic markers in patients with cirrhosis and portal hypertension who have not bled. Dis Markers 2011;31:147-154.

-3 Steib CJ, Gerbes AL, Bystron M, Op den WM, Hartl J, Roggel F, Prufer T, Goke B, Bilzer M: Kupffer cell activation in normal and fibrotic livers increases portal pressure via thromboxane A(2). J Hepatol 2007;47:228238 .
4 Steib CJ, Gmelin L, Bilzer M, Göke B, Gerbes AL: Portal pressure regulation following Kupffer cell activation: control of prostaglandin production by heme oxygenases. Digestion 2013;87: 102-109.

5 Tsuchihashi S, Fondevila C, Kupiec-Weglinski JW: Heme oxygenase system in ischemia and reperfusion injury. Ann Transplant 2004;9:84-87.
6 Amersi F, Shen XD, Anselmo D, Melinek J, Iyer S, Southard DJ, Katori M, Volk HD, Busuttil RW, Buelow R, Kupiec-Weglinski JW: Ex vivo exposure to carbon monoxide prevents hepatic ischemia/reperfusion injury through p38 MAP kinase pathway. Hepatology 2002;35:815-823.

7 Brouwer KLR, Thurman RG: Isolated perfused liver; in Borchardt RT, Smith PL, Wilson G (eds): Models for Assessing Drug Absorption and Metabolism. Pharmaceutical Biotechnology. New York, Plenum Press, 1996, vol 8, pp 161-192. 